\title{
REVIEW
}

\section{Conditional transgenic technologies}

\author{
A D S Ryding, M G F Sharp and J J Mullins \\ Molecular Physiology Group, University of Edinburgh Medical School, Wilkie Building, Teviot Place, Edinburgh EH8 9AG, UK \\ (Requests for offprints should be addressed to A D S Ryding; Email: alisdair.ryding@ed.ac.uk)
}

\begin{abstract}
Transgenic technology has been revolutionised by the development of techniques that allow temporo-spatial control of gene deletion or expression in transgenic animals. The ability to switch gene expression 'on' or 'off' in restricted tissues at specific times allows unprecedented flexibility for exploring gene function in both health and
\end{abstract}

disease. As use of these techniques grows in all areas of biomedical research, an understanding of this topic is essential. In this review we examine the theory, application and limitations of these strategies, with particular reference to endocrine research.

Journal of Endocrinology (2001) 171, 1-14

\section{Introduction}

Conventional transgenic technologies (gene overexpression or knockouts) are invaluable for modelling genetic disorders and answering specific questions in relation to developmental biology. However, this 'all or nothing' approach is inflexible and cannot be used to answer more subtle questions about gene function. Frequently, a genetic change has developmental consequences that either preclude or complicate studies on adult animals (e.g. embryonic lethality). Furthermore, conventional knockout strategies affect every cell in an animal, so that it is often impossible to distinguish primary and secondary changes in a complex phenotype. In order to tease out more precise information about the role of a gene in a specific cell type at a critical stage of disease or development, a more sophisticated approach is required. Building on conventional transgenic techniques, conditional technologies allow flexible temporo-spatial control of gene expression. In these systems the switching 'on' or 'off of a particular gene is conditional on a specific stimulus. Such techniques are increasingly applied to endocrine problems, providing elegant models to study physiology and disease. An appreciation of the principles involved is essential for researchers in this field.

This review will concentrate on the theory, application and problems of established conditional transgenic strategies. A basic knowledge of conventional transgenesis is assumed, and a good review of this is provided by Bronson \& Smithies (1994).

\section{Conditional overexpression}

Tetracycline responsive system

The ideal conditional overexpression system should allow the investigator to switch transgene expression on and off, rapidly, reversibly, at any point during development or postnatal life, and only in the desired cell type. Many systems have been developed harnessing the inherent responsiveness of specific promoters to various stimuli, such as heat shock and steroid hormones (Gossen et al. 1993). However, in most cases the effects of the stimulus are too profound and non-specific to offer any practical in vivo application.

Pioneering work by Bujard and Gossen has established the tetracycline transactivator system as a reliable tool for regulated transgene expression. This exploits pathways that control the expression of a tetracycline resistance gene in E. coli. This gene is constitutively repressed by tetracycline repressor (tetR), a protein that binds specifically to tetracycline operator (tet $\mathrm{O})$ sequences within the promoter, rendering the gene transcriptionally silent. Repression is relieved by tetracycline, which avidly binds tetR (Fig. 1a and b). In this way, tetracycline resistance is controlled in a simple on/off manner by tetracycline itself (Gossen et al. 1993).

Because tetR and tet $\mathrm{O}$ interact specifically with each other and do not overlap with eukaryotic systems, they avoid many of the problems that have beset previous attempts to regulate transgene expression. Two modifications have been made to suit transgenic purposes (Gossen \& Bujard 1992). First, tetR has been converted 
a)

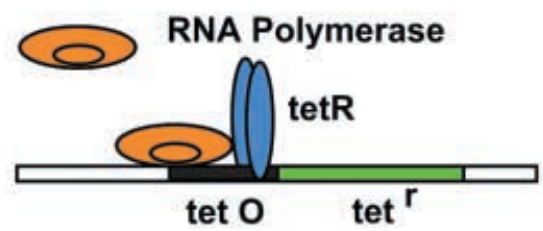

c)

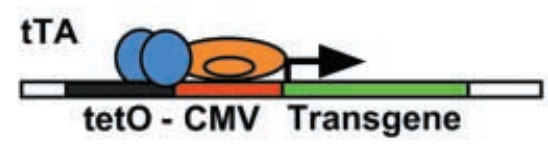

b)

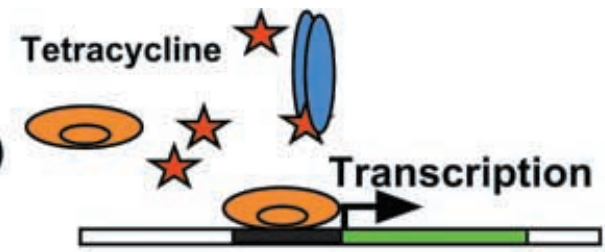

d)

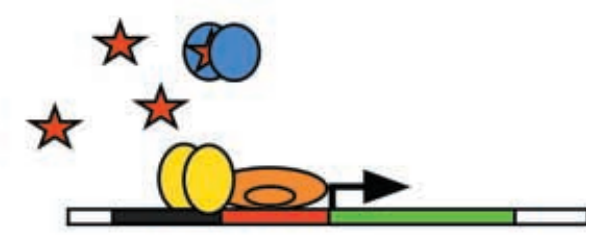

\title{
No Tetracycline
}

\section{Tetracycline}

\begin{abstract}
Figure 1 ( $\mathrm{a}$ and $\mathrm{b}$ ) Regulation of the tetracycline resistance operon. (a) tetR dimers bind tetO sequences upstream of the tetracycline resistance gene preventing transcription initiation by RNA polymerase. (b) Binding of tetR by tetracyline relieves transcriptional inhibition, leading to expression of the tetracycline resistance gene. Blue elipses, tetR dimer; dark grey bar, tetO sequences; green bar, tetracycline resistance gene; orange, RNA polymerase; red star, tetracycline. (c and d) Tetracycline-regulated transgene expression. (c) Tetracycline absent. tTA binds the tetO-CMV promoter turning on transgene transcription. In contrast, rtTA is inactive and there is no transgene expression. (d) Tetracycline present. Tetracycline has opposite effects on tTA and rtTA: tetracycline inhibits binding of tTA at the promoter, turning off expression (tet-off system). In the presence of tetracycline, rtTA induces transgene expression (tet-on system). It should be noted that doxycycline is used in practice for regulating the rtTA system. Blue circles, tTA; yellow, rtTA; black and red bars, tetO-CMV promoter; green, transgene; orange, transcription complex; tet ${ }^{r}$, tetracycline resistance gene.
\end{abstract}

into a transcriptional activator by fusing it with the activation domains of the herpes simplex virus VP16 protein. VP16 is a virally encoded factor that recruits cellular transcription factors and potently activates viral transcription (Herr 1998). The hybrid molecule is termed the tetracycline transcriptional activator (tTA). The second modification is the use of a cytomegalovirus (CMV)derived minimal promoter, fused with tet $\mathrm{O}$ sequences to control transgene expression. This chimaeric promoter is transcriptionally silent in basal conditions, and is induced in the presence of tTA and tetracycline (Fig. 1c). Tetracycline inactivates tTA and causes transgene downregulaton (Fig. 1d).

Many variants of the tTA system have been designed with specific properties: these are summarised in Table 1. Reverse tTA (rtTA) is a mutagenised version which binds tet $\mathrm{O}$ in the presence of doxycycline and activates transcription (Gossen et al. 1995) (Fig. 1c and d). In other words, the effects of doxycyline are the opposite of tTA. The major advantage of this is that gene induction occurs

Table 1 Tetracycline-regulated expression systems. Activity is enhanced (+) or suppressed $(-)$ by doxycycline

\begin{tabular}{|c|c|c|c|}
\hline & Activity & $\begin{array}{l}\text { Response to } \\
\text { doxycycline }\end{array}$ & Reference \\
\hline \multicolumn{4}{|l|}{ Type } \\
\hline tTA & Activator & - & Gossen \& Bujard (1992) \\
\hline rtTA & Activator & + & Gossen et al. (1995) \\
\hline $\mathrm{RtTA}^{\mathrm{s}}-\mathrm{M} 2$ & Activator & + & Urlinger et al. (2000a) \\
\hline rtTE & Activator & + & Akagi et al. (2001) \\
\hline $\mathrm{tTS}^{\mathrm{kid}}$ & Repressor & - & Freundlieb et al. (1995) \\
\hline tTR & Repressor & - & Zhu et al. (2001) \\
\hline
\end{tabular}


rapidly because the low levels of doxycycline required for transcriptional activation are readily achieved. In contrast, the kinetics of gene induction by tTA are somewhat slower, since clearance of doxycycline can take days in animals. However, a limitation is that rtTA retains some affinity for tet $\mathrm{O}$ sequences even in the absence of doxycycline: this leads to low level basal expression, which may not be acceptable (e.g. expression of toxins) (Keyvani et al. 1999, Imhof et al. 2000). To overcome this problem, tet-repressors have been designed. Two constructs, $\mathrm{tTS}^{\mathrm{kid}}$ and tTR, are available in which the repressor domain of tetR has been substituted with a mammalian equivalent. These repress transcriptional activity at tet $\mathrm{O}$ sequences in the absence of tetracycline (Freundlieb et al. 1995, Rossi et al. 1998, Sander et al. 2000). Used in combination with rtTA, complete suppression of transgene expression can be achieved in vivo without compromising inducibility (Zhu et al. 2001). An obvious disadvantage of this approach is that triple transgenic animals are required. An alternative method has been to engineer improvements in rtTA by a combination of random mutagenesis, use of minimal transactivating domains and codon optimisation for mammalian cells. The variant RtTA2 $-\mathrm{M} 2$ was generated in this manner. This has virtually no background activity, enhanced doxycycline sensitivity and improved transcript stability (Urlinger et al. 2000a,b). However, evidence of improved performance in transgenic mice is still preliminary. Finally, substitution of the VP16 moiety of rtTA with the transactivation domain of the mammalian transcription factor E2F4 appears to be tolerated better by mammalian cells (Akagi et al. 2001).

The tetracycline analogues, doxycycline and anhydrotetracycline, tend to be used in preference to tetracycline itself due to higher tTA binding affinities and lower toxicities (Gossen \& Bujard 1993, Efrat et al. 1995, A-Mohammadi et al. 1997).

Tet-regulated transgenic mice Use of this system in mice requires the generation of two independent transgenic strains: one carrying the transgene of interest under the control of the tet $\mathrm{O}-\mathrm{CMV}$ promoter, and the other an (r)t TA transgene. Crossing the lines generates a proportion of progeny with both transgenes, allowing regulation of the gene of interest through the administration of tetracycline (Fig. 2).

Initial studies in mice transgenic for tTA or rtTA crossed with luciferase or $\beta$-galactosidase reporter strains demonstrated both the practicality and problems of this approach (Furth et al. 1994, Kistner et al. 1996). Between different transgenic lines, reporter expression varied, probably reflecting variation in chromosomal integration sites and transgene copy number. In many lines, significant leaky expression was found. However, in selected lines basal expression levels were close to the limits of detection. Expression could be induced up to 100 000-fold in certain tissues and, in rtTA transgenics, kinetic studies showed
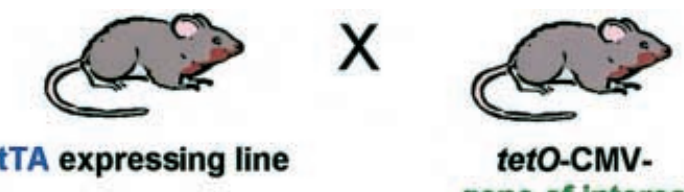

teto-CMVgene of interest

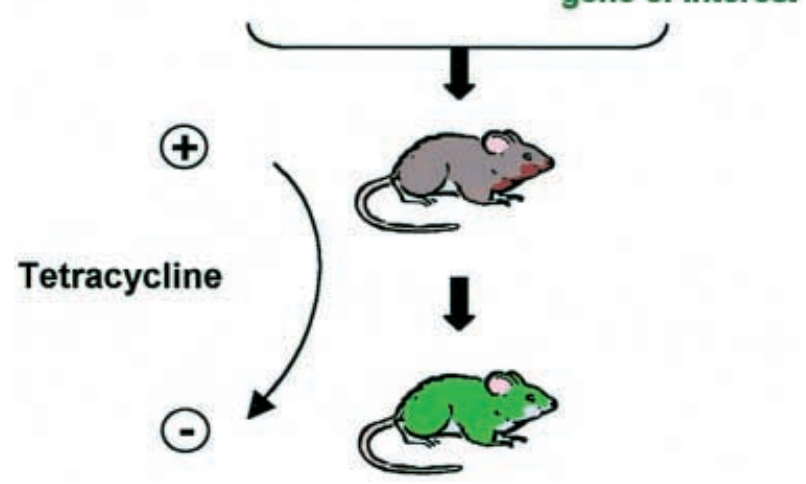

Figure 2 tTA transgenic mice. Mice transgenic for tTA crossed to mice transgenic for a tet-regulated gene produce progeny in which tetracycline suppresses transgene expression. Withdrawal of tetracycline leads to induction of transgene expression (green).

Tissue specificity is conferred by the promoter driving tTA expression.

significant induction within hours of oral doxycycline administration. With tTA, transgenic changes in expression occurred over days, due to the reasons mentioned above. Transgene expression could be switched on and off repeatedly without adverse effect. Histological analysis revealed mosaic expression of $\beta$-galactosidase within tissues when tTA was under the control of a CMV promoter (Furth et al. 1994), but this problem has not been seen using a strong tissue-specific promoter (Kistner et al. 1996).

Tissue-specific promoters allow expression of the transactivator to be restricted to a particular tissue or cell type. Defining the site of expression of the transactivator determines the site of transgene expression, because the minimal promoter itself confers no tissue specificity. It should be noted that the expression pattern of a promoter can be strongly influenced by the chromosomal context in which it integrates. Therefore, it is important to screen for ectopic expression. This can be done by screening for expression of the transgene itself, or using transgenic reporter lines (e.g. $\beta$-galactosidase) which allow visualisation of the expression pattern. An alternative approach is to use a bi-directional minimal promoter to drive expression of both the transgene and the reporter in the same animal (Baron et al. 1995, Yamamoto et al. 2000). This avoids the need to cross to additional lines, and gives an indirect measure of transgene expression.

The fine regulation of transgenes afforded by this system has been used to great advantage in numerous studies. This is best exemplified by experiments where neonatal lethality has been by-passed by delaying expression to later 
time-points. For example, overexpression of the BCRABL1 oncogene (BCR-ABL) during development is lethal. Huettner et al. (2000) used the tTA system to induce $\mathrm{BCR}-\mathrm{ABL}$ expression in B-lymphocytes in adult animals, resulting in acute leukaemia. Silencing transgene expression allowed complete resolution of the leukaemia, a process that could be reversed many times. Conditional activation of toxic transgenes has also been used to ablate specific cell populations: Lee et al. (1998) conditionally expressed diphtheria toxin A chain in cardiac cells leading to cell ablation and progressive cardiomyopathy. By contrast, Efrat et al. (1995) conditionally transformed islet $\beta$-cells with SV40 T antigen creating pancreatic tumours from which cell lines were derived.

Additional regulatory control can be built into experiments. For example, Redfern et al. (1999) created a modified kappa opioid receptor that only recognises a synthetic ligand, spiradoline. This modified G proteincoupled receptor activates $\mathrm{Gi}$ signalling in response to spiradoline. Using tissue-specific promoters, enhanced Gi signalling was targeted to the heart, liver and salivary gland in separate transgenic lines. In long-term experiments, chronic Gi signalling led to dilated cardiomyopathy which was partially reversible (Redfern et al. 2000). Bond et al. (2000) recently described a method of using the tTA system to control native gene expression. In this way, a reversible cell-specific 'virtual knockout' was generated. By homologous recombination, a tetracycline-based control cassette was placed in the $5^{\prime}$ untranslated region of the SK3 gene (encoding a subunit of a $\mathrm{Ca}^{2+}$-activated $\mathrm{K}^{+}$ channel). Expression of tTA was under the control of the native regulatory elements of SK3. Expression of SK3 itself was in turn contingent upon expression of tTA, and could be abolished by administering doxycycline. However, disruption of the native locus led to elevated expression of the conditional allele in the brain in the basal state, although the pattern of expression was not altered. This allowed them to either augment or switch off SK3 expression.

Despite these impressive studies, certain limitations are increasingly recognised, such as leaky expression, cellular toxicity, unstable transcripts and insensitivity to doxycycline in certain tissues (Baron et al. 1997, Urlinger et al. 2000a). It is hoped that developments such as the RtTA2 $2^{\text {s }} \mathrm{M} 2$ variant will circumvent these problems. In addition, it should be noted that the genetic background of mice can influence the occurrence of such difficulties ( $\mathrm{Zhu}$ et al. 2001). Another drawback is the need to generate two separate transgenic lines for each study. Schultze et al. (1996) have used a single construct containing all the necessary regulatory sequences and transgene on one plasmid. Theoretically, this approach is less time consuming and avoids the segregation of control elements during breeding. However, the use of double transgenic lines is more flexible if one wishes to make use of several different tissue-specific transactivator lines to study the effects of a single transgene.

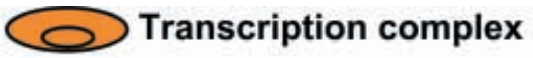

a)
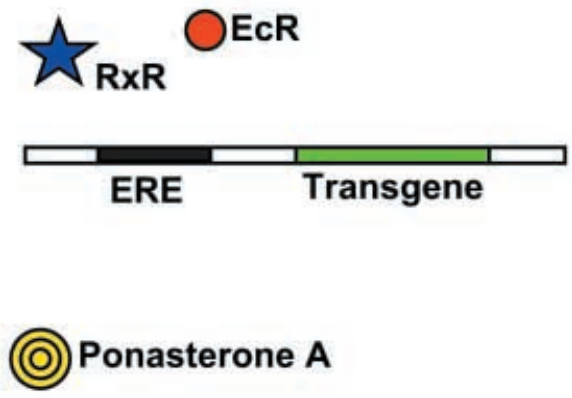

b)

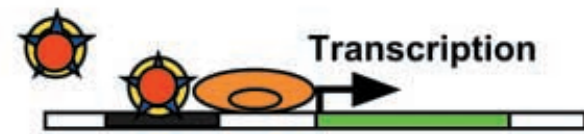

Figure 3 Ecdysone-regulated transgene expression. (a) In the absence of ponasterone $A$ the modified EcR does not bind the ERE. (b) Ponasterone A activates transgene expression by inducing dimerisation of EcR and the RXR, allowing binding to the ERE and recruitment of transcription factors. Red, modified EcR; black bar, ERE; yellow, ponasterone A; blue star, RXR; green, transgene; orange, transcription complex.

The wealth of transactivators and tetracycline analogues available with different properties theoretically allows independent regulation of more than one transgene in a single animal using combinations of the tetracycline system. The feasibility of this has been demonstrated in cell lines (Baron et al. 1999) although not in vivo.

It should also be noted that the various components of this system are now commercially available, making it highly accessible.

\section{Ecdysone-inducible overexpression}

Ecdysone is a steroid hormone that triggers metamorphosis in insects. It mediates pleiotropic effects via a heterodimeric receptor, comprising the ecdysone receptor $(\mathrm{EcR})$ and the product of the ultraspiracle gene (USP) which together bind ecdysone response elements (ERE) to enhance transcription of genes required for metamorphosis. No et al. (1996) have adapted this system for mammalian cells in a manner analogous to the tet system described above. A novel transactivator was generated by fusion of a truncated EcR with transcriptional activation domains of the glucocorticoid receptor and the herpes simplex virus VP16. This hybrid retains specificity for binding ecdysone and ERE, but has enhanced transcriptional activity. In addition, a novel ecdysone-specific response element was constructed that allowed inducible gene expression without cross reactivity with endogenous mammalian nuclear hormone receptors. The retinoid $\mathrm{X}$ receptor (RXR) is the mammalian homologue of USP, and functions effectively with the hybrid EcR (Fig. 3). 
Experiments in transfected cells and transgenic mice have demonstrated the potential use of this system. Mice transgenic for hybrid EcR and RXR under the control of $\mathrm{T}$-lymphocyte promoters were crossed with reporter mice bearing an ecdysone-inducible $\beta$-galactosidase transgene. Basal reporter expression was minimal, but could be rapidly induced by intraperitoneal injection of a synthetic ecdysone analogue, muristerone A. Muristerone has not been found to exert any teratogenic or physiological effects in mice. More recently, a widely available natural plant steroid, ponasterone $\mathrm{A}$, has been shown to be a potent and innocuous inducing agent (Saez et al. 2000). The use of synthetic RXR ligands synergises with muristerone induction (Saez et al. 2000), although the use of such compounds may have unwanted physiological effects. Hoppe et al. (2000a) have simplified the system using a chimaeric Drosophila/Bombyx ecdysone receptor which transactivates transgenes without the need for RXR at all.

In vitro comparison of the ecdysone and tetracycline induction systems demonstrated lower basal expression, greater inducibility and more rapid induction kinetics with ecdysone (No et al. 1996). In the uninduced state, there may even be transcriptional repression of the transgene which makes this system less leaky then tet-based ones (Rossant \& McMahon 1999). However, direct in vivo comparison has not been carried out.

So far this technology has been used most extensively in cell culture systems and examples of ecdysone-based transgenics are sparse. Albanese et al. (2000) have successfully targeted expression of an ecdysone-responsive $\beta$ galactosidase transgene to the mammary gland. Similarly, Saez et al. (2000) directed inducible luciferase expression to the skin with a human keratin 5 promoter. Other in vivo work has been limited to adenoviral-mediated transfer of ecdysone-inducible constructs to the heart and carotid bodies (Hoppe et al. 2000b).

Until further studies are reported, the advantages of this system cannot be evaluated. However, the benefit of having more than one inducible system available is the potential for combination transgenics with multiple independently regulated transgenes.

\section{Cytochrome P-450 induction system}

An inherent drawback of the systems described above is the requirement for doubly-transgenic animals. Use of endogenous mammalian gene regulatory systems can avoid this complexity. For example, the mouse metallothionein promoter has been used for many years to regulate transgene expression (Palmiter et al. 1983). Transcription at this promoter is induced by heavy metal ions such as zinc and cadmium. However, there is invariably highlevel constitutive expression in a broad range of tissues, and the degree of transgene induction is relatively poor (Joseph et al. 1999). For these reasons, this system will not be a)

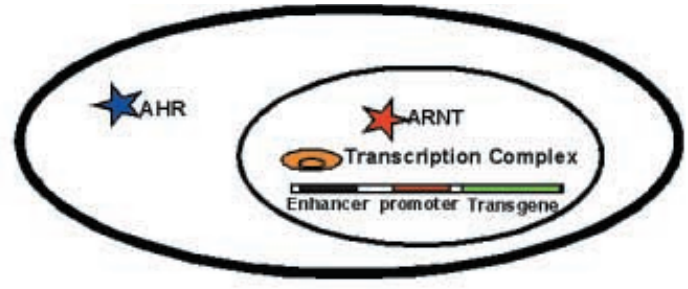

b)

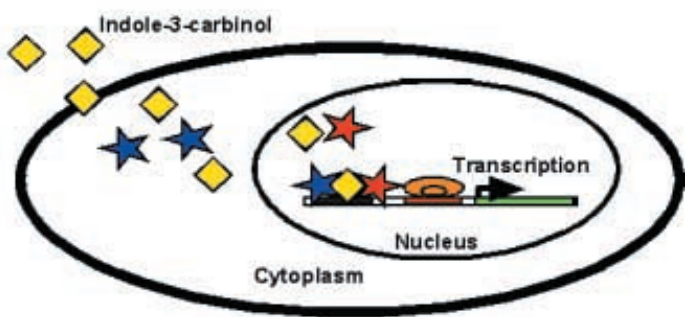

Figure 4 Cyp1a1 promoter/enhancer regulation. (a) In the absence of inducing agent cyp $1 \mathrm{a} 1$ is transcriptionally silent. (b) Aryl hydrocarbons such as I3C induce cyp1a1 gene transcription by binding cytoplasmic AHR, translocating to the nucleus and complexing with ARNT. Here the complex binds aryl hydrocarbon responsive elements (ARE) within the enhancer region leading to alterations in chromatin structure around the promoter which enhance transcription factor recruitment. Blue star, AHR; red star, ARNT; yellow, I3C; black bar, ARE; red, promoter; green, transgene; orange, transcription complex.

discussed further. In contrast, the cytochrome P-450 system is highly inducible and provides more stringent control of gene expression.

Cytochrome P-450 mono-oxygenases are enzymes involved in metabolising and detoxifying lipophilic xenobiotics (Gonzalez \& Nebert 1990). Expression of some P-450 enzymes is directly regulated by the availability of their substrate. In other words, exposure to a specific compound will induce expression of the cytochrome responsible for its metabolism. One such cytochrome, CYP1A1 (encoding aryl hydrocarbon (benzo[a]pyrene) hydroxylase (E.C.1·14.14.1)) is induced by aryl hydrocarbons and the enhancer/promoter sequences of this gene have been used successfully for conditional transgene expression.

CYP1A1 is not expressed constitutively and it is regulated entirely at a transcriptional level (Ryu et al. 1996). Induction requires binding of aryl hydrocarbon compounds to aryl hydrocarbon receptors (AHR) in the cytoplasm. AHR-ligand complexes shuttle to the nucleus where they bind to the aryl hydrocarbon nuclear translocator (ARNT), forming a heterodimer-ligand complex. Both AHR and ARNT are ligand-dependent basic helixloop-helix transcription factors that bind aromatic hydrocarbon-responsive elements (AhREs) several hundred base pairs upstream of the cyp1a1 promoter (Fig. 4). AhRE binding induces chromatin remodelling at 
the promoter which favours transcription (Elferink \& Whitlock 1990, Fujii-Kuriyama et al. 1995, Okino \& Whitlock 1995). Chromatin structure is also important in maintaining transcriptional silence in the uninduced state (Okino \& Whitlock 1995). AHR and ARNT are expressed predominantly in the liver (Dolwick et al. 1993, Li et al. 1994), and both are essential for cyp 1a1 induction (Ryu et al. 1996, Foussat et al. 1998, Zaher et al. 1998, Tomita et al. 2000).

This system has been characterised in transgenic mice and rats using various portions of the cyp $1 a 1$ enhancer promoter. Small parts of the promoter region fail to control transgene expression adequately (Jones et al. 1991, Shachter et al. 1994, Smith et al. 1995a) whilst more extensive portions which include all the known enhancer/ promoter sequences allow tightly regulated expression (Campbell et al. 1996, Kantachuvesiri et al. 2001). As for any transgene, the site of chromosomal integration has a profound effect on the level of baseline expression: many transgenic lines may have to be screened in order to identify a suitable one. Transgene expression can be induced in a dose-dependent manner as much as 10000 fold (Jones et al. 1991). Expression is predominantly in the liver, but also adrenal, kidney, intestine, spleen, lung, pancreas, skin and the reproductive organs (Campbell et al. 1996, Kantachuvesiri et al. 2001). Within each tissue, expression is regulated in a cell-type specific manner (Campbell et al. 1996). The widespread expression reflects the tissue distribution of AHR and ARNT: this may be less than ideal for some applications.

In our laboratory, we have used the rat cyp $1 a 1$ enhancer/promoter sequences to control mouse Ren2 cDNA (encoding renin) expression in rats (Kantachuvesiri et al. 2001). This has created an inducible model of hypertension. Background expression levels are undetectable in non-induced rats. Blood pressure can be titrated in a dose-dependent manner to produce either malignant or chronic phase hypertension. Furthermore, the reninangiotensin system and blood pressure return to normal in the absence of inducer, making this an extremely flexible model for studying hypertension, vascular injury and repair.

One prerequisite for a useful regulatory system is that the inducer must be innocuous, and that spillover activation of other loci is inconsequential. Most AHR-binding compounds have deleterious effects, but indole-3-carbinol (I3C) is an exception. This is a naturally occurring aryl hydrocarbon found in brassicae. It has anticarcinogenic, antioestrogenic, hypocholesterolaemic and immunomodulatory effects which are poorly understood (Dunn \& LeBlanc 1994, Bradlow et al. 1999, Exon \& South 2000). I3C itself is a weak inducer of cyp $1 a 1$ but derivatives formed in the stomach are much more potent: up to 24 different active metabolites have been found in rats fed I3C (Stresser et al. 1995). Since it is readily absorbed and metabolised, induction of cyp1a1 occurs within hours
(Stresser et al. 1995). It also induces other members of the aryl hydrocarbon battery including CYP1A2, CYP2B1/2 and CYP3A1/2, and inhibits both the activity and expression of flavin mono-oxygenase 1 (Katchamart et al. 2000): thus, metabolism of other xenobiotics is undoubtedly affected and this may interfere with pharmacological studies. Futhermore, in vitro studies on a hepatoma cell line indicated that induction of CYP1A1 with an I3C derivative can lead to oxidative DNA damage (Park et al. 1996). Despite these multiple effects, chronic oral administration in adult rats and mice has been shown to be safe.

The simplicity and robustness of this system make it eminently suitable for overexpression of secreted soluble proteins. However, limited tissue specificity restricts its broader application.

\section{Conditional genetic deletion: somatic cell mutagenesis}

Embryonic lethality in many conventional gene knockouts impedes attempts to study gene function in older animals. One way of avoiding this is to ablate specific genes at later stages of development or adulthood using recombinases. Two members of the $\alpha$ integrase family of site-specific recombinases, Cre and Flp, have proved invaluable for conditional transgenic use.

Cre (causes recombination) recombinase of the P1 bacteriophage directs recombination between loxP (locus of crossover) sites. Its function is to maintain phage-encoding plasmids as monomers. In a similar manner the Flp integrase of Saccharomyces cerevisiae mediates recombination between FRT (FLP recombination target) sites within yeast plasmids (Kilby et al. 1993). In each case, the only requirements for DNA rearrangement are the integrase and the recombination sites: no additional cellular factors are necessary. Both loxP and FRT sites are $34 \mathrm{bp}$ DNA sequences comprising two $13 \mathrm{bp}$ palindromes separated by an asymmetric $8 \mathrm{bp}$ core. The recombinases catalyse DNA strand exchange between two aligned recombination sites, resulting in deletion, duplication, integration, inversion or translocation of sequences, according to the orientation of the recombination sites and the number of molecules involved (Fig. 5).

Application of these techniques in mice allows deletion of genetic material in selected cells at a specific time. In this way, one can avoid the complications of embryonic lethality and developmental compensatory changes. At its most simple, this requires incorporation of two recombination sites within a gene of interest, and then expression of a recombinase in only those cells in which one wishes deletion to occur. Because this technology relies on homologous recombination in embryonic stem cells, its use is restricted to mice. 
Intramolecular Deletion.

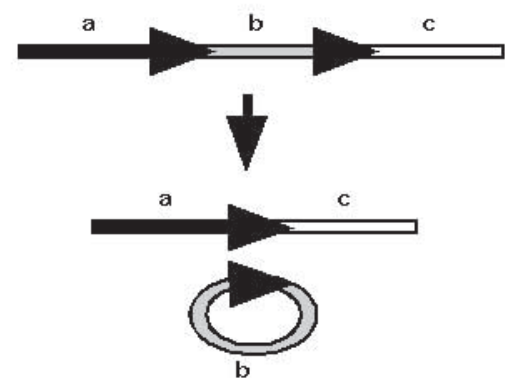

Intermolecular Deletion / Duplication.

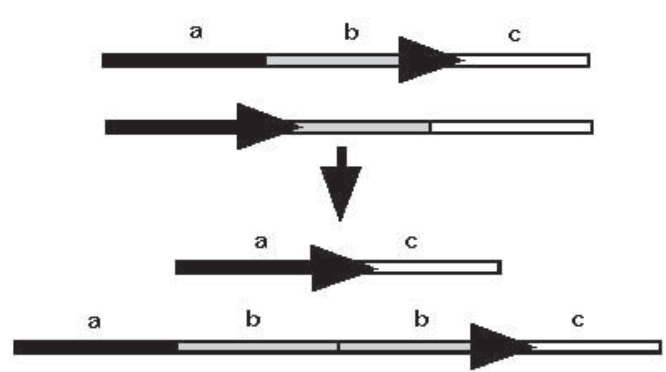

Inversion.

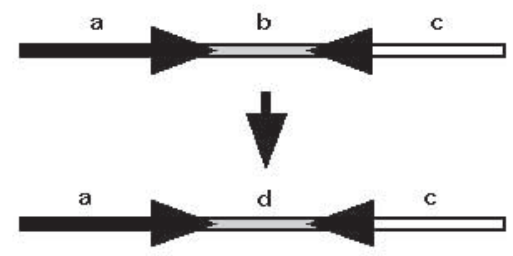

Integration.

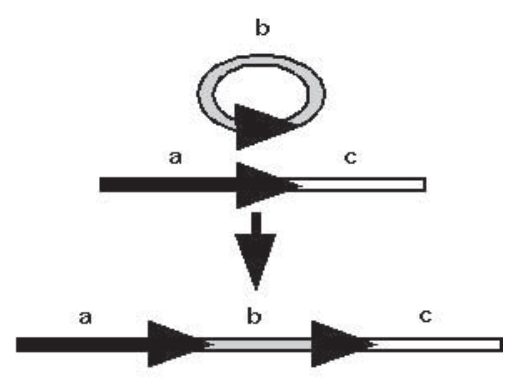

\section{lox P or Frt site}

Figure 5 Cre/Flp-mediated recombination reactions. Site-specific recombinases mediate inter- and intramolecular recombination reactions leading to deletion, duplication, inversion or integration events.

\section{Cre-lox system}

Modification of a specific gene with loxP sites flanking the region of interest is achieved using standard gene targeting vectors in embryonic stem (ES) cells. Such an allele is said to be 'floxed' (flanked by loxP) and depending on the exact position of the lox $P$ sites and selection markers, may or may not be fully functional. Mice derived from these targeted ES cells can be bred to homozygosity for the floxed allele, and crossing with other mice transgenic for Cre recombinase under the control of a specific promoter allows time- or tissue-specific deletion of the floxed segment (Fig. 6). In this way, the activity of the gene can be modified in a limited range of cells at a particular developmental stage, whilst the genetic content of the rest of the animal is essentially unaltered. Crossing to a different Cre transgenic mouse line allows the generation of a different temporo-spatial pattern of recombination, and possibly phenotype (Fig. 6).

This strategy has been used extensively since Lakso et al. (1992) first described the Cre-mediated activation of an SV40 T antigen transgene in lens cells leading to tumour formation. Tissue specificity is determined by the choice of promoter driving Cre recombinase expression. Many tissue-specific Cre transgenic and floxed mice strains are becoming available, and a database cataloguing such animals is available at http://www.mshri.on.ca/nagy/ cre.htm: from this it can be seen that many important endocrine tissues can be selectively targeted, although the list is far from complete. Tissue-specific Cre-lox techniques have yielded unexpected insights into endocrine physiology in recent years. Table 2 gives published examples of Cre-loxP-mediated gene deletion in endocrine tissues or target tissues. Cre-lox strategies can also facilitate cell fate-mapping studies. Using Cre recombination to genetically tag the progeny of pancreatic stem cells, Herrera (2000) demonstrated separate developmental lineages for $\alpha$ and $\beta$ cells.

Ideally one would wish to control not only the site of recombination but also the timing. Several strategies have been designed to address this, using inducible forms of Cre recombinase. Fusion of the ligand-binding domain (LBD) of a mutated oestrogen receptor to Cre results in a hybrid that is active in the presence of tamoxifen, but not endogenous steroids (Metzger et al. 1995). The LBD allows sequestration of hybrid Cre in the cytosol by heat-shock proteins. Tamoxifen liberates the recombinase, allowing recombination to proceed at a specified time in tissues expressing Cre. Similar hybrids have been developed using modified progesterone and glucocorticoid 


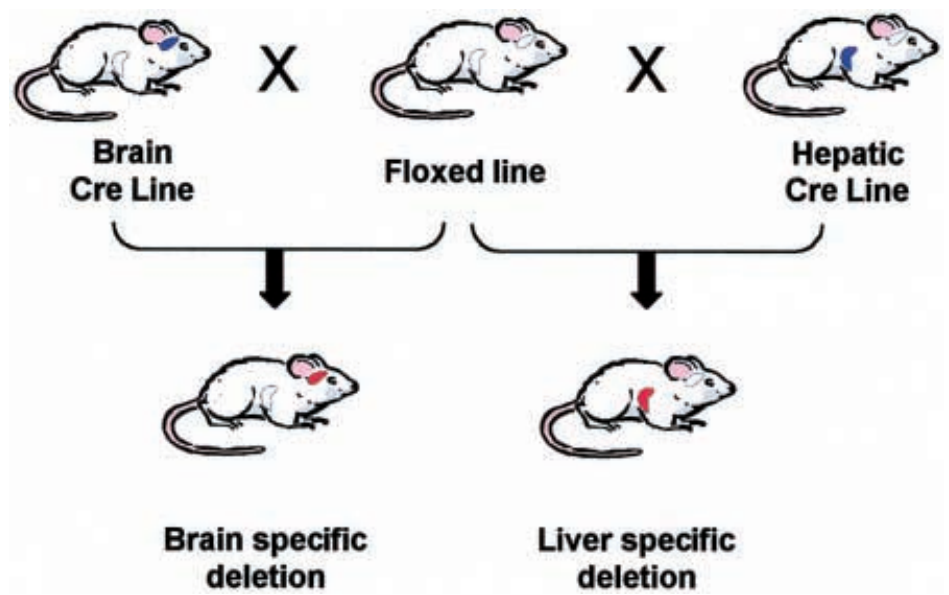

Figure 6 Tissue-specific gene ablation using Cre-lox. Mouse lines expressing Cre (blue) in a tissue-restricted manner, such as the brain or liver, can be crossed to a line containing a floxed allele. Cre-mediated recombination results in allele deletion in the brain or liver alone, leading to altered function (red).

receptor LBDs, responsive to RU486 and dexamethasone respectively (Kellendonk et al. 1996, Brocard et al. 1998). Validation of ligand-activated Cre in transgenic mice demonstrated no detectable recombination in the absence of tamoxifen (Feil et al. 1996) but almost 100\% recombination in Cre-expressing cells after 3 days of exposure (Brocard et al. 1997). However, in some cases incomplete and ligand-independent recombination have been observed (Schwenk et al. 1998, Kellendonk et al. 1999). New forms of tamoxifen and RU486-inducible Cre are now available with enhanced ligand sensitivity and low background activity (Indra et al. 1999, Kuhbandner et al. 2000, Imai et al. 2001, Wunderlich et al. 2001). Thus ligand-activated Cre shows great promise for controlling the timing of recombination. Since tamoxifen is only given for a brief time, no lasting complications arise, and it has even been used with pregnant mice (Danielian et al. 1998).

An alternative strategy for inducing Cre activity is to use an inducible promoter. Tetracycline-regulated expression of Cre has been used by several groups. For example, Shin et al. (1999) successfully ablated endothelin $\mathrm{B}$ receptors (EDNRB) in mice at various time-points and were able to define a critical developmental period in which EDNRB is essential. Tetracycline-inducible tissuespecific knockouts are also possible (Saam \& Gordon 1999, Utomo et al. 1999). Kuhn et al. (1995) have used an interferon-inducible promoter to control Cre expression,

Table 2 Studies using Cre-loxP-mediated gene deletion in endocrine tissues or target tissues

\begin{tabular}{|c|c|c|}
\hline & Tissue-specificity & Phenotype \\
\hline \multicolumn{3}{|l|}{ Disrupted gene } \\
\hline C/ebpa & Liver & Impaired gluconeogenesis and bilirubin metabolism \\
\hline \multirow[t]{2}{*}{ Glucocorticoid receptor } & Glia & Altered HPA regulation \\
\hline & & Reduced anxiety behaviour \\
\hline \multirow[t]{3}{*}{ Glucokinase } & Liver & Defective glycogen synthesis \\
\hline & & Impaired insulin secretion \\
\hline & Pancreatic $\beta$ cells & Fatal hyperglycaemia \\
\hline GLUT4 & Adipose tissue & Hepatic and skeletal muscle insulin resistance \\
\hline IGF1 & Liver & $\begin{array}{l}\text { Skeletal muscle insulin resistance } \\
\text { Normal postnatal growth }\end{array}$ \\
\hline Insulin receptor & Pancreatic $\beta$ cells & Impaired insulin release: impaired glucose tolerance \\
\hline \multirow[t]{2}{*}{ Insulin receptor } & Skeletal muscle & Altered fat metabolism \\
\hline & & Preserved glucose tolerance \\
\hline PTHrP & Global & Perinatal lethality: aberrant endochondral bone formation \\
\hline \multirow[t]{2}{*}{$R \times R a$} & Adipose tissue & Obesity resistance \\
\hline & & Impaired lipolysis \\
\hline SF1 & Anterior pituitary & Hypogonadotrophic hypogonadism \\
\hline
\end{tabular}

Reference

Lee et al. (1997)

Tronche et al. (1999)

Postic et al. (1999)

Abel et al. (2001)

Yakar et al. (2001)

Yakar et al. (1999)

Kulkarni et al. (1999)

Brüning et al. (1998)

He et al. (2001)

Imai et al. (2001)

Zhao et al. (2001) 
and this has been used successfully to delete the low density lipoprotein receptor-related protein in hepatocytes (Rohlmann et al. 1998). Adenoviral delivery of Cre can also be used to determine the timing of recombination in certain tissues: after systemic delivery most recombination occurs within the liver, none in the central nervous system, and intermediate levels in other tissues (Wang et al. 1996, Akagi et al. 1997). However, immune responses to adenovirus limit the permanence of Cre expression (Akagi et al. 1997).

Cre-lox has been used most extensively for small-scale DNA rearrangements affecting single loci. However, it can also orchestrate chromosomal rearrangements, such as deletion of large regions, or translocations (Smith et al. 1995b, Clerc \& Avner 1998, Buchholz et al. 2000, Collins et al. 2000, Su et al. 2000, Zheng et al. 2000). Deletion between loxP sites in cis can extend up to at least 60 centimorgan $(\mathrm{cM})$ in $\mathrm{ES}$ cells in vitro. In vivo, a cardiac-specific $2 \mathrm{cM}$ deletion has been demonstrated (Zheng et al. 2000). Such manipulations are very attractive for loss of heterozygosity studies and screens for tumour suppressor genes. Both deletion and duplication of regions within the Hox gene cluster has been achieved by inducing unequal exchanges between homologous chromosomes at loxP sites (Herault et al. 1998). Such exchanges can be engineered to cause whole chromosome loss by generating acentric/dicentric chromosomes (Lewandoski \& Martin 1997). Anti-parallel loxP sites have been used to invert regulatory elements within the HoxD complex, resulting in dysregulation of limb and gut development (Kmita et al. 2000).

It is clear from most Cre-lox mouse experiments that there are several potential pitfalls. First, expression of Cre within a particular cell type or tissue is rarely uniform, leading to mosaic recombination. In certain instances this may be desirable or at least inconsequential, in so far as it models random somatic mutagenesis (e.g. carcinogenesis). However, for some physiological studies, even remnant levels of wild-type product may not be acceptable. Determining the extent of recombination is essential for interpreting experiments. In tissues of heterogeneous cell type, Southern blotting may be an inadequate method of analysis because it does not indicate the cell type in which recombination has occurred. In situ PCR for the floxed allele or immunohistochemistry for Cre expression are alternatives that give some indication of cell specificity (Selbert et al. 1998). Reporter strains for Cre activity such as ROSA26- $\beta$ geo (Mao et al. 1999, Soriano 1999) in which an activatable floxed $\beta$ geo has been knocked-in to the ubiquitously expressed ROSA26 locus, give a clear indication of the sites and extent of recombination for a particular Cre transgenic. Alternative reporter strains with activatable enhanced green fluorescent protein (GFP) are also available (Kawamoto et al. 2000, Mao et al. 2001). 'Double-reporter' lines have been developed that constitutively express $L a c Z$ throughout development and adult- hood: Cre-mediated recombination inactivates the $L a c Z$ transgene whilst activating a second reporter such as GFP or alkaline phosphatase (Lobe et al. 1999, Novak et al. 2000). A major assumption of reporter strains is that they accurately reflect recombination for other floxed loci. However, recombination efficiency is known to vary between different target loci (Holzenberger et al. 2000a) so results obtained in this manner can only be a guide. One solution is to design the initial targeting vector in such a way that recombination leads to activation of a reporter gene (Kmita et al. 2000, Moon \& Cappechi 2000). This has the advantage of giving a direct read-out of recombination efficiency within the animal under study.

A second problem is that of transcriptional interference by vector-derived sequences, such as the neo selection cassette, or even the loxP sites. Tronche et al. (1999) found that the floxed glucocorticoid allele gave rise to levels of expression twice as high as wild type, whilst others have found underexpression (Fiering et al. 1995, Olson et al. 1996, McDevitt et al. 1997, Nagy et al. 1998, Holzenberger et al. 2000a,b). Such alleles are referred to as 'knockdown' or 'hypomorphic'. Intermediate expression levels may be informative (Meyers et al. 1998, Holzenberger et al. 2000b), but this is unpredictable. Cryptic splicing of plasmid sequences can also create abnormal transcripts (Yu et al. 1998) which may have unexpected effects (Meyers et al. 1998, Forlino et al. 1999). Vectors can be designed to allow the removal of unwanted plasmid sequences from cultured ES cells prior to blastocyst injection (Xu et al. 1999). However, the extended period of culture required may theoretically interfere with ES cell pluripotency. Alternatively, mice expressing Cre in the testes have been used successfully for excision of floxed plasmid sequence in germline chimaeras (O'Gorman et al. 1997, Blume-Jensen et al. 2000, Holzenberger et al. 2000a).

In most circumstances, mammalian cells appear surprisingly tolerant of Cre recombinase expression and DNA rearrangements. However, several studies have indicated that Cre can act efficiently at endogenous pseudo-loxP sites identified within mammalian genomes (Thyagarajan et al. 2000). Schmidt et al. (2000) found that mice expressing Cre in spermatids were sterile due to gross chromosomal rearrangements that may have been caused by this mechanism. Although this problem has not been reported in somatic cells its occurrence may have less dramatic consequences and it has therefore escaped attention. For this reason it would seem sensible to restrict Cre expression as far as possible: one approach has been to design self-excising Cre cassettes (Bunting et al. 1999).

Despite these caveats, Cre-lox technology has revolutionised genetic analysis of mice and is now well established as a routine genetic tool. It should be considered the first choice for conditional gene deletion experiments. 


\section{FLP recombinase}

The uses of Flp mirror those already established for Cre; conditional gene knockouts, transgene activation, selection cassette removal, chromosomal rearrangement and mapping studies. The same cautions regarding mosaicism and ectopic expression are also pertinent. However, use of Flp in transgenic mice is at a less advanced stage than that of Cre and a direct comparison between the two is not possible at this time.

Dymecki (1996) has demonstrated dose-dependent Flpmediated recombination in a FRT-lac $Z$ reporter strain, and elegantly used Wnt 1 promoter-driven Flp to fate-map neuronal migrations in the developing brain (Dymecki \& Tomasiewicz 1998, Rodriguez \& Dymecki 2000). Exhaustive analysis of the pattern and extent of Flp expression/recombination events demonstrated high levels of recombination $(>90 \%)$ in a highly restricted cell-type specific pattern (Rodriguez \& Dymecki 2000). Vooijs et al. (1998) conditionally ablated the retinoblastoma gene in anterior pituitary cells, leading to adenoma formation. In this study, a modified form of Flp was used, and the efficiency of recombination was far less than $100 \%$.

Concern that the recombination efficiency of Flp is inferior to that of Cre has been allayed somewhat since the development of an enhanced, mutant form (FLPe) (Buchholz et al. 1998). This exhibits fourfold greater activity than wild type, and maximally excises a target gene in a broadly expressing reporter line (Rodriguez et al. 2000). No ubiquitously expressing reporter lines for Flp are currently available, and this is another disadvantage compared with Cre.

As for Cre, an oestrogen-LBD-Flp hybrid has been developed to allow rapidly inducible recombination activity (Logie \& Stewart 1995, Logie et al. 1998). However, activity of the hybrid is only $50 \%$ that of the wild-type enzyme.

Use of Flp and Cre in combination allows sophisticated manipulation of loci: for example, removal of unwanted plasmid sequences from a conditional allele at the ES cell stage with Flp/FRT, and subsequent deletion by Cre in vivo (Moon \& Cappechi 2000). Meyers et al. (1998) ingeniously used both to create an allelic series at the Fgf8 locus. A floxed hypomorphic allele could be knocked out completely using conditional Cre, or reverted back to wild type using Flp. One can easily envisage many more situations where multiple simultaneous or sequential conditional mutations are created using recombinase combinations, either at single or multiple loci. However, whilst $\mathrm{Flp} / \mathrm{FRT}$ is an increasingly attractive system, it does not yet have the track record of Cre-lox.

\section{Discussion and Conclusions}

The phenotypic modification of monogenic disorders by the genetic background of inbred laboratory animals has been recognised for many years. Under identical environmental conditions, such observations may be attributable to one or more 'modifier loci' that increase or decrease the severity of a phenotype (Nadeau 2001). Formal identification and analysis of modifiers may provide a novel insight into the biology of a disease, for which there are numerous examples in the literature (Kantachuvesiri et al. 1999, Nadeau 2001).

Genetic background is of great importance in conditional transgenic experiments because it may influence not only the primary pathology but also the efficiency of the conditional system itself. For example, evidence already suggests that the regulation of the rtTA system differs between mouse strains (Zhu et al. 2001). In a similar manner, one might anticipate that the efficiency of Cre recombination is strain dependent, although this has not been formally investigated. Complications of this nature may have unpredictable and misleading consequences, particularly when different conditional models on different inbred backgrounds are intercrossed (genetic multiplexing). For this reason every effort should be made to maintain pure genetic backgrounds.

The availability of reliable conditional transgenic technologies is set to revolutionise our understanding of physiology and disease. This comes at an opportune time, when advances in genome sequencing, array technology and miniaturised physiological assessment will provide both the raw material and the means for analysis. Conditional techniques should be seen as supplementing rather than supplanting conventional transgenesis, which remains an invaluable tool.

Theoretically one may choose to overexpress or delete genes in specified tissues at will. Choosing between the available systems depends very much on the goals of the experiment and available expertise. However, some systems have well-established track records and should probably be the first choice unless there are special experimental considerations. In practice, these experiments are a considerable investment of time and resources without guarantee of success. Problems still remain to be resolved, such as mosaic, ectopic and leaky expression, necessitating careful characterisation and quantification of transgene expression patterns (e.g. using reliable reporter lines or built-in reporters). With the growing availability of complementary transgenic lines (e.g. Cre/Flp, floxed/ FRT, tet/ecdysone) convenient inter-crossing experiments of ever greater complexity will be possible.

\section{Acknowledgements}

We acknowledge the support of the Wellcome Trust and the British Heart Foundation. A R is the holder of a Wellcome Trust Cardiovascular Initiative Clinical Training Fellowship (062859/HS). M S ia a BHF Basic Science Lecturer and $\mathrm{J} M$ is a Wellcome Trust Principal Research 
Fellow. Thanks are due to Mark Lawson for assistance with figures.

\section{References}

Abel ED, Peroni O, Kim JK, Kim Y-B, Boss O, Hadro E, Minnemann T, Shulman GI \& Kahn BB 2001 Adipose-selective targeting of the GLUT4 gene impairs insulin action in muscle and liver. Nature 409 729-733.

Akagi K, Sandig V, Vooijs M, Van der Valk M, Giovannini M, Strauss M \& Berns A 1997 Cre-mediated somatic site-specific recombination in mice. Nucleic Acids Research 25 1766-1773.

Akagi K, Kanai M, Saya H, Kozu T \& Berns A 2001 A novel tetracycline-dependent transactivator with E2F4 transcriptional activation domain. Nucleic Acids Research 29 e23.

Albanese C, Reutens AT, Bouzahzah B, Fu M, D’Amico M, Link T, Nicholson R, Dephino RA \& Pestell RG 2000 Sustained mammary gland-directed, ponasterone A-inducible expression in transgenic mice. FASEB Journal 14 877-884.

A-Mohammadi S, Alvarez-Vallina L, Ashworth LJ \& Hawkins RE 1997 Delay in resumption of the activity of tetracycline-regulatable promoter following removal of tetracycline analogues. Gene Therapy 4 993-997.

Baron U, Freundlieb S, Gossen M \& Bujard H 1995 Co-regulation of two gene activities by tetracycline via a bidirectional promoter. Nucleic Acids Research 23 3605-3606.

Baron U, Gossen M \& Bujard H 1997 Tetracycline-controlled transcription in eukaryotes: novel transactivators with graded transactivation potential. Nucleic Acids Research 25 2723-2729.

Baron U, Schnappinger D, Helbl V, Gossen M, Hillen W \& Bujard H 1999 Generation of conditional mutants in higher eukaryotes by switching between the expression of two genes. PNAS 96 1013-1018.

Blume-Jensen P, Jiang G, Hyman R, Lee KF, O'Gorman S \& Hunter T $2000 \mathrm{Kit} / \mathrm{stem}$ cell factor receptor-induced activation of phosphatidyl 3'-kinase is essential for male fertility. Nature Genetics 24 157-162.

Bond CT, Sprengel R, Bissonnette JM, Kauffmann WA, Pribnow D, Neelands T, Storck T, Baetscher M, Jerecic J, Maylie J, Knaus H-G, Seeburg PH \& Adelman JP 2000 Respiration and parturition affected by conditional overexpression of the $\mathrm{Ca}^{2+}$-activated $\mathrm{K}^{+}$ channel subunit, SK3. Science 289 942-946.

Bradlow HL, Sepkovic DW, Telang NT \& Osborne MP 1999 Multifunctional aspects of the action of indole-3-carbinole as an antitumour agent. Annals of the New York Academy of Sciences $\mathbf{8 8 9}$ 204-213.

Brocard J, Warot X, Wendling O, Messaddeo N, Vonesch J-L, Chambon P \& Metzger D 1997 Spatio-temporally controlled site-specific somatic mutagensis in the mouse. PNAS 94 14559-14563.

Brocard J, Feil R, Chambon P \& Metzger D 1998 A chimeric Cre recombinase inducible by synthetic, but not natural ligands of the glucocorticoid receptor. Nucleic Acids Research 26 4086-4090.

Bronson SK \& Smithies O 1994 Altering mice by homologous recombination using embryonic stem cells. Journal of Biological Chemistry $26927155-27158$.

Brüning JC, Michael MD, Winnay JN, Hayashi T, Horsch D, Accili D, Goodyear LJ \& Kahn CR 1998 A muscle-specific insulin receptor knockout exhibits features of the metabolic syndrome of NIDDM without altering glucose tolerance. Molecular Cell 2 559-569.

Buchholz F, Angrand PO \& Stewart AF 1998 Improved properties of FLP recombinase evolved by cycling mutagenesis. Nature Biotechnology 16 657-662.

Buchholz F, Refaeli Y, Trumpp A \& Bishop JM 2000 Inducible chromosomal translocation of AML1 and ETO genes through
Cre/loxP-mediated recombination in the mouse. EMBO Reports 1 133-139.

Bunting M, Bernstein KE, Greer JM, Capecchi MR \& Thomas KR 1999 Targeting genes for self-excision in the germline. Genes and Development 13 1524-1528.

Campbell SJ, Carlotti F, Hall PA, Clark AJ \& Wolf CR 1996 Regulation of the CYP1A1 promoter in transgenic mice: an exquisitely sensitive on-off system for cell specific gene regulation. Journal of Cell Science 109 2619-2625.

Clerc P \& Avner P 1998 Role of the region 3' to Xist exon 6 in the counting process of X-chromosome inactivation. Nature Genetics 19 249-253.

Collins EC, Pannell R, Simpson EM, Forster A \& Rabbitts TH 2000 Inter-chromosomal recombination of Mll and Af9 genes mediated by cre-loxP in mouse development. EMBO Reports 1 127-132.

Danielian PS, Muccino D, Rowitch DH, Michael SK \& McMahon AP 1998 Modification of gene activity in mouse embryos in utero by a tamoxifen-inducible form of Cre recombinase. Current Biology 8 1323-1326.

Dolwick KM, Schmidt JV, Carver LA, Swanson HI \& Bradfield CA 1993 Cloning and expression of a human Ah receptor cDNA. Molecular Pharmacology 44 911-917.

Dunn SE \& LeBlanc GA 1994 Inhibition of Acyl-CoA:cholesterol acyltransferase activity and reduction of serum LDL/VLDL cholesterol levels by glucobrassin derivatives. Biochemical Pharmacology 47 359-364.

Dymecki SM 1996 Flp recombinase promotes site-specific DNA recombination in embryonic stem cells and transgenic mice. PNAS 93 6191-6196.

Dymecki SM \& Tomasiewicz H 1998 Using Flp-recombinase to characterise expansion of Wnt1-expressing neural progenitors in the mouse. Developmental Biology 201 57-65.

Efrat S, Fusco-DeMane D, Lemberg H, Emran OL \& Wang X 1995 Conditional transformation of a pancreatic $\beta$-cell line derived from transgenic mice expressing a tetracycline-regulated oncogene. PNAS 92 3576-3580.

Elferink J \& Whitlock JP Jr 1990 2,3,7,8-Tetrachlorodibenzo-pdioxin-inducible, Ah receptor-mediated bending of enhancer DNA. Journal of Biological Chemistry 265 5718-5721.

Exon JH \& South EH 2000 Dietary indole-3-carbinol alters immune function in rats. Journal of Toxicology and Environmental Health Assessment $59271-279$.

Feil R, Brocard J, Mascrez B, LeMur M, Metzger D \& Chambon P 1996 Ligand-activated site-specific recombination in mice. PNAS 93 10887-10890.

Fiering S, Epner E, Robinson K, Zhuang Y, Telling A, Hu M, Martin DIK, Enver T, Ley TJ \& Groudine M 1995 Targeted deletion of $5^{\prime} \mathrm{HS} 2$ of the murine $\beta$-globin LCR reveals that it is not essential for proper regulation of the $\beta$-globin locus. Genes and Development 9 2203-2213.

Forlino A, Porter FD, Lee EJ, Westphal H \& Marini JC 1999 Use of the Cre/lox recombination system to develop a non-lethal knock-in murine model for osteogenesis imperfecta with an $\alpha 1$ (I) G349C substitution. Journal of Biological Chemistry 274 37923-37931.

Foussat J, Costet P, Galtier P, Pineau T \& Lesca P 1998 The 4S benzo(a)pyrene-binding protein is not a transcriptional activator of Cyp1a1 gene in Ah receptor-deficient (AHR-/-) transgenic mice. Archives of Biochemistry and Biophysics 349 349-355.

Freundlieb S, Schirra-Muller G \& Bujard H 1995 A tetracycline controlled activation/repression system with increased potential for gene transfer into mammalian cells. Journal of Genetic Medicine 1 4-12.

Fujii-Kuriyama Y, Ema M, Mimura J, Matsushita N \& Sogawa K 1995 Polymorphic forms of the Ah receptor and induction of the CYP1A1 gene. Pharmacogenetics 5 S149-S153.

Furth PA, St-Onge L, Boger H, Gruss P, Gossen M, Kistner A, Bujard H \& Hennighausen L 1994 Temporal control of gene expression in transgenic mice by a tetracycline-responsive promoter. PNAS 91 9302-9306. 
Gonzalez FJ \& Nebert DW 1990 Evolution of the P450 gene superfamily: animal-plant 'warfare', molecular drive and human genetic differences in drug oxidation. Trends in Genetics 6 182-186.

Gossen G \& Bujard H 1992 Tight control of gene expression in mammalian cells by tetracycline-responsive promoters. PNAS $\mathbf{8 9}$ $5547-5551$.

Gossen M \& Bujard H 1993 Anhydrotetracycline, a novel effector of the tetracycline controlled gene expression systems in eukaryotic cells. Nucleic Acids Research 21 4411-4412.

Gossen M, Bonin AL \& Bujard H 1993 Control of gene activity in higher eukaryotic cells by prokaryotic regulatory elements. Trends in Biochemical Sciences 18 471-475.

Gossen M, Freundlieb S, Bender G, Muller G, Hillen W \& Bujard H 1995 Transcriptional activation by tetracyclines in mammalian cells. Science 268 1766-1769.

He B, Deckelbaum RA, Miao D, Lipman ML, Pollak M, Goltzman D \& Karaplis C 2001 Tissue-specific targeting of the pthrp gene: the generation of mice with floxed alleles. Endocrinology 142 2070-2077.

Herault Y, Rassoulzadegan M, Cuzin F \& Duboule D 1998 Engineering chromosomes in mice through targeted meiotic recombination (TAMERE). Nature Genetics 20 381-384.

Herr W 1998 The herpes simplex virus VP16-induced complex: mechanisms of combinatorial transcriptional regulation. Cold Spring Harbor Symposia on Quantitative Biology 63 599-607.

Herrera PL 2000 Adult insulin- and glucagon-producing cells differentiate from two independent cell lineages. Development 127 2317-2322.

Holzenberger M, Lenzner C, Leneuve P, Zaoui R, Hamard G, Vaulont S \& Le Bouc Y 2000a Cre-mediated germline mosaicism: a method allowing rapid generation of several alleles of a target gene. Nucleic Acids Research 28 e92.

Holzenberger M, Leneuve P, Hamard G, Ducos B, Perin L, Binoux M \& Le Bouc Y $2000 b$ A targeted partial invalidation of the insulin-like growth factor receptor gene in mice causes a postnatal growth deficit. Endocrinology 141 2557-2566.

Hoppe UC, Marban E \& Johns DC 2000a Adenovirus-mediated inducible gene expression in vivo by a hybrid ecdysone receptor. Molecular Therapentics 1 159-164.

Hoppe UC, Marban E \& Johns DC $2000 b$ Molecular dissection of cardiac repolarization by in vivo $\mathrm{Kv} 4 \cdot 3$ gene transfer. Journal of Clinical Investigation 105 1077-1084.

Huettner CS, Zhang P, van Etten RA \& Tenen DG 2000 Reversibility of acute B-cell leukaemia induced by BCR-ABL1. Nature Genetics 24 57-60.

Imai T, Jiang M, Chambon P \& Metzger D 2001 Impaired adipogenesis and lipolysis in the mouse upon selective ablation of the retinoid $\mathrm{X}$ receptor $\alpha$ mediated by a tamoxifen-inducible chimeric Cre recombinase $\left(\mathrm{Cre}-\mathrm{ER}^{\mathrm{T} 2}\right.$ ) in adipocytes. PNAS $\mathbf{9 8}$ 224-228.

Imhof MO, Chatellard P \& Mermod N 2000 A regulatory network for the efficient control of transgene expression. Journal of Genetic Medicine 2 107-116.

Indra AK, Warot X, Brocard J, Bornert J, Bornert JM, Xiao JH, Chambon P \& Metzger D 1999 Temporally-controlled sitespecific mutagenesis in the basal layer of the epidermis: comparison of the recombinase activity of the tamoxifen-inducible Cre-ER(T) and Cre-ER(T2) recombinases. Nucleic Acids Research 27 4324-4327.

Jones SN, Jones PG, Ibarguen H, Caskey CT \& Craigen WJ 1991 Induction of the Cyp1a1 dioxin-responsive enhancer in transgenic mice. Nucleic Acids Research 19 6547-6551.

Joseph H, Gorska AE, Sohn P, Moses HL \& Serra R 1999 Overexpression of a kinase-deficient transforming growth factor- $\beta$ type II receptor in mouse mammary stroma results in increased epithelial branching. Molecular Biology of the Cell 10 1221-1234.
Kantachuvesiri S, Haley CS, Fleming S, Kurian K, Whitworth CE, Wenham P, Kotelevtsev Y \& Mullins JJ 1999 Genetic mapping of modifier loci affecting malignant hypertension in TGRmRen2 rats. Kidney International 56 414-420.

Kantachuvesiri S, Fleming S, Peters J, Peters B, Brooker G, Lammie AG, McGrath I, Kotelevtsev Y \& Mullins JJ 2001 Controlled hypertension: a transgenic toggle switch reveals differential mechanisms underlying vascular disease. Journal of Biological Chemistry (In Press).

Katchamart S, Stresser DM, Dehal SS, Kupfer D \& Williams DE 2000 Concurrent flavin-containing monooxygenase down-regulation and cytochrome P-450 induction by dietary indoles in rat: implications for drug-drug interaction. Drug Metabolism and Disposition 28 930-936.

Kawamoto S, Niwa H, Tashiro F, Sano S, Kondoh G, Takeda J, Tabayashi K \& Miyazaki J-I 2000 A novel reporter mouse strain that expresses enhanced green fluorescent protein upon Cremediated recombination. FEBS Letters 470 263-268.

Kellendonk C, Tronche F, Monagha A-P, Angrand P-O, Stewart F \& Schutz G 1996 Regulation of Cre recombinase activity by the synthetic steroid RU 486. Nucleic Acids Research 24 1404-1411.

Kellendonk C, Tronche F, Casanova E, Anlag K \& Opherk C 1999 Inducible site-specific recombination in the brain. Journal of Molecular Biology 285 175-182.

Keyvani K, Baur I \& Paulus W 1999 Tetracycline-controlled expression but not toxicity of an attenuated diphtheria toxin mutant. Life Science 64 1719-1724.

Kilby NJ, Snaith MR \& Murray JAH 1993 Site-specific recombinases: tools for genome engineering. Trends in Genetics 9 413-421.

Kistner A, Gossen M, Zimmermann F, Jerecic J, Ullmer C, Lubbert $\mathrm{H} \&$ Bujard J 1996 Doxycycline-mediated quantitative and tissue-specific control of gene expression in transgenic mice. PNAS 93 10933-10938.

Kmita M, Kondo T \& Duboule D 2000 Targeted inversion of a polar silencer within the HoxD complex re-allocates domains of enhancer sharing. Nature Genetics 26 451-454.

Kuhbandner S, Brummer S, Metzger D, Chambon P, Hofmann F \& Feil R 2000 Temporally controlled somatic mutagenesis in smooth muscle. Genesis 28 15-22.

Kuhn R, Schwenk F, Aguet M \& Rajewsky K 1995 Inducible gene targeting in mice. Science 269 1427-1429.

Kulkarni R, Brüning JC, Winnay J, Postic C, Magnuson M \& Kajn C 1999 Tissue-specific knockout of the insulin receptor in pancreatic $\beta$ cells creates an insulin secretory defect similar to that in type 2 diabetes. Cell 96 329-339.

Lakso M, Sauer B, Mosinger B, Lee EJ, Manning RW, Yu S-H, Mulder KL \& Westphal H 1992 Targeted oncogene activation by site specific recombination in transgenic mice. PNAS $\mathbf{8 9} 6232-6236$.

Lee P, Morley G, Huang Q, Fischer A, Seiler S, Horner JW, Factor S, Vaidya D, Jalife J \& Fishman GI 1998 Conditional lineage ablation to model human disease. PNAS 95 11371-11376.

Lee Y-H, Sauer B, Johnson PF \& Gonzalez FJ 1997 Disruption of the c/ebpa gene in adult mouse liver. Molecular and Cellular Biology 17 6014-6022.

Lewandoski M \& Martin GR 1997 Cre-mediated chromosome loss in mice. Nature Genetics 17 223-225.

Li H, Dong L \& Whitlock JP Jr 1994 Transcriptional activation function of the mouse Ah receptor nuclear translocator. Journal of Biological Chemistry $26928098-28105$.

Lobe CG, Koop KE, Kreppner W, Lomeli H, Gerstsenstein M \& Nagy A 1999 Z/AP, a double reporter for cre-mediated recombination. Developmental Biology 208 281-292.

Logie C \& Stewart AF 1995 Ligand-regulated site-specific recombination. PNAS 92 5940-5944.

Logie C, Nichols M, Myles K, Funder JW \& Stewart AF 1998 Positive and negative discrimination of estrogen receptor agonists and antagonists using site-specific DNA recombinase fusion proteins. Molecular Endocrinology 12 1120-1132. 
McDevitt MA, Shivdasani RA, Fujiwara Y \& Yang H 1997 A 'knockdown' mutation created by cis-element gene targeting reveals the dependence of erythroid cell maturation on the level of transcription factor GATA-1. PNAS 94 6781-6785.

Mao X, Fujiwara Y \& Orkin SH 1999 Improved reporter strain for monitoring Cre recombinase-mediated DNA excisions in mice. PNAS 96 5037-5042.

Mao X, Fujiwara Y, Chapdelaine A, Yang H \& Orkin SH 2001 Activation of EGFP expression by cre-mediated excision in a new ROSA26 reporter mouse strain. Blood 97 324-326.

Metzger D, Clifford J, Chiba H \& Chambon P 1995 Conditional site-specific recombination in mammalian cells using a liganddependent chimeric Cre recombinase. PNAS 92 6991-6995.

Meyers EN, Lewandoski M \& Martin GR 1998 An Fgf8 mutant allelic series generated by Cre- and Flp-mediated recombination. Nature Genetics 18 136-141.

Moon AM \& Cappechi MR 2000 Fgf8 is required for outgrowth and patterning of the limbs. Nature Genetics 26 455-459.

Nadeau JH 2001 Modifier genes in mice and humans. Nature Reviews Genetics 2 165-174.

Nagy A, Moens C, Ivanyi E, Pawling J, Gerstenstein M, Hadjantonakis A-K, Pirity M \& Rossant J 1998 Dissecting the role of $\mathrm{N}-m y c$ in development using a single targeting vector to generate a series of alleles. Current Biology 8 661-664.

No D, Yao T-P \& Evans RM 1996 Ecdysone-inducible gene expression in mammalian cells and transgenic mice. PNAS $\mathbf{9 3}$ 3364-3351.

Novak A, Guo C, Yang W, Nagy A \& Lobe CG 2000 Z/EG, a double reporter mouse line that expresses enhanced green fluorescent protein upon cre-mediated excision. Genesis 28 147-155.

O'Gorman S, Dagenais NA, Qian M \& Marchuk Y 1997 ProtamineCre recombinase transgenes efficiently recombine target sequences in the male germ line of mice, but not in embryonic stem cells. PNAS 94 14602-14607.

Okino ST \& Whitlock JP 1995 Dioxin induces localised, graded changes in chromatin structure: implications for Cyp 1a1 gene transcription. Molecular and Cellular Biology 15 3714-3721.

Olson EN, Arnold H-H, Rigby PWJ \& Wold BJ 1996 Know your neighbors: three phenotypes in null mutants of the myogenic bHLH gene MRF4I. Cell 85 1-4.

Palmiter RD, Norstedt G, Gelinas RE, Hammer RE \& Brinster RL 1983 Metallothionein-human GH fusion genes stimulate growth of mice. Science 222 809-814.

Park J-YK, Shigenaga MK \& Ames BN 1996 Induction of cytochrome P4501A1 by 2,3,7,8-tetrachlorodibenzo-p-dioxin or indolo $(3,2-b)$ carbazole is associated with oxidative DNA damage. PNAS 93 2322-2317.

Postic C, Shiota M, Niswender KD, Jetton TL, Chen Y, Moates JM, Shelton KD, Lindner J, Cherrington AD \& Magnuson MA 1999 Dual roles for glucokinase in glucose homeostasis as determined by liver and pancreatic $\beta$-cell-specific gene knock-outs using Cre recombinase. Journal of Biological Chemistry 274 305-315.

Redfern CH, Coward P, Dedtyarev MY, Lee EK, Kwa AT, Henninghausen L, Bujard H, Fishman GI \& Conklin BR 1999 Conditional expression and signalling of a specifically designed $\mathrm{G}_{\mathrm{i}}$-coupled receptor in transgenic mice. Nature Biotechnology 17 165-169.

Redfern CH, Degtyarev MY, Kwa AT, Salomonis N, Cotte N, Nanevicz T, Fidelman N, Desai K, Vranizan K, Lee EK, Coward P, Shah N, Warrington JA, Fishman GI, Bernstein D, Baker AJ \& Conklin BR 2000 Conditional expression of a $\mathrm{G}_{\mathrm{I}}$-coupled receptor causes ventricular conduction delay and a lethal cardiomyopathy. PNAS 97 4826-4831.

Rodriguez CI \& Dymecki SM 2000 Origin of the precerebellar system. Neuron 27 475-486.
Rodriguez CI, Buchholz F, Galloway J, Sequerra R, Kasper J, Ayala R, Stewart AF \& Dymecki SM 2000 High-efficiency deleter mice show that FLPe is an alternative to Cre-loxP. Nature Genetics $\mathbf{2 5}$ 139-140.

Rohlmann A, Gotthardt M, Hammer RE \& Herz J 1998 Inducible inactivation of hepatic LRP gene by Cre-mediated recombination confirms a role of LRP in clearance of chylomicron remnants. Journal of Clinical Investigation 101 689-695.

Rossant J \& McMahon A 1999 'Cre'-ating mouse mutants - a meeting review on conditional mouse genetics. Genes and Development 13 142-145.

Rossi FMV, Guichert OM, Spicher A, Kringstein AM, Fatoyl K, Blakely BT \& Blau HM 1998 Tetracycline-regulatable factors with distinct dimerization domains allow reversible growth inhibition by p16. Nature Genetics 20 389-393.

Ryu DY, Levi PE, Fernandez-Salguero P, Gonzalez FJ \& Hodgson E 1996 Piperonyl butoxide and acenaphthylene induce cytochrome P450 1A2 and 1B1 mRNA in aromatic hydrocarbon-responsive receptor knock-out mouse liver. Molecular Pharmacology 50 443-446.

Saam JR \& Gordon JI 1999 Inducible gene knockouts in the small intestinal and colonic epithelium. Journal of Biological Chemistry 274 38071-38082.

Saez E, Nelson MC, Eshelman B, Banayo E, Koder A, Cho GI \& Evans RM 2000 Identification of ligands and coligands for the ecdysone-regulated gene switch. PNAS 97 14512-14517.

Sander A, Guth A, Brenner HR \& Witzemann V 2000 Gene transfer into individual muscle fibers and conditional gene expression in living animals. Cell and Tissue Research 301 397-403.

Schmidt EE, Taylor DS, Prigge JR, Barnett S \& Capecchi MR 2000 Illegitimate Cre-dependent chromosome rearrangements in transgenic mouse spermatids. PNAS 97 13702-13707.

Schultze N, Burki Y, Lang Y, Certa U \& Bluethmann H 1996 Efficient control of gene expression by single step integration of the tetracycline system in transgenic mice. Nature Biotechnology 14 499-503.

Schwenk F, Kuhn R, Angran P-O, Rajewsky K \& Stewart AF 1998 Temporally and spatially regulated somatic mutagenesis in mice. Nucleic Acids Research 26 1427-1432.

Selbert S, Bentley DJ, Melton DW, Rannie D, Lourenco P, Watson CJ \& Clarke AR 1998 Efficient BLG-Cre mediated gene deletion in the mammary gland. Transgenic Research 7 387-396.

Shachter NS, Hayek T, Leff T, Smith JD, Rosenberg DW, Walsh A, Ramakrishnan R, Goldberg IJ, Ginsberg HN \& Breslow JL 1994 Overexpression of apolipoprotein CII causes hypertriglyceridemia in transgenic mice. Journal of Clinical Investigation 93 1683-1690.

Shin MK, Levorse JM, Ingram RS \& Tilghman SM 1999 The temporal requirement for endothelin receptor-B signalling during neural crest development. Nature 402 496-501.

Smith JD, Wong E \& Ginsberg M 1995a Cytochrome P450 1A1 promoter as a genetic switch for the regulatable and physiological expression of a plasma protein in transgenic mice. PNAS 92 11926-11930.

Smith AJH, De Sousa MA, Kwavi-Addo A, Heppell-Parton H, Impey H \& Rabbitts P 1995b A site-directed chromosomal translocation induced in embyonic stem cells by Cre-loxP recombination. Nature Genetics 9 376-385.

Soriano P 1999 Generalised lac Z expression with the ROSA26 Cre reporter strain. Nature Genetics 21 70-71.

Stresser DM, Williams DE, Griffin DA \& Bailey GS 1995 Mechanisms of tumour modulation by indole-3-carbinol. Disposition and excretion in male Fischer 344 rats. Drug Metabolism and Disposition 23 965-975.

Su H, Wang X \& Bradley A 2000 Nested chromosomal deletions induced with retroviral vectors in mice. Nature Genetics 24 92-95.

Thyagarajan B, Guimaraes MJ, Groth AC \& Calos MP 2000 Mammalian genomes contain active recombinase recognition sites. Gene 244 47-54. 
Tomita S, Sinal CJ, Yim SH \& Gonzalez FJ 2000 Conditional disruption of the aryl hydrocarbon receptor nuclear translocator (Arnt) gene leads to loss of target gene induction by the aryl hydrocarbon receptor and hypoxia-inducible factor 1 alpha. Molecular Endocrinology 14 1674-1681.

Tronche F, Kellendonk C, Kretz O, Gas P, Anlag K, Orban PC, Bock R, Klein R \& Schutz G 1999 Disruption of the glucocorticoid receptor gene in the nervous system results in reduced anxiety. Nature Genetics 23 99-103.

Urlinger S, Baron U, Thellmann M, Hasan MT, Bujard H \& Hillen W 2000a Exploring the sequence space for tetracycline-dependent transcriptional activators: novel mutations yield expanded range and sensitivity. PNAS 97 7963-7968.

Urlinger S, Helbl V, Guthmann J, Pook A, Grimm S \& Hillen W $2000 \mathrm{~b}$ The p65 domain of NF-kB is an efficient human activator in the tetracycline-regulatable gene expression system. Gene $\mathbf{2 4 7}$ 103-110.

Utomo AR, Nikitin AY \& Lee WH 1999 Temporal, spatial, and cell-type specific control of Cre-mediated DNA recombination in transgenic mice. Nature Biotechnology 17 1091-1096.

Vooijs M, van der Valk M, te Riele H \& Berns A 1998 Flp-mediated tissue-specific inactivation of the retinoblastoma tumor suppressor geme in the mouse. Oncogene 17 1-12.

Wang Y, Krushel LA \& Edelman GM 1996 Targeted DNA recombination in vitro using an adenovirus carrying the Cre recombinase gene. PNAS 93 3932-3936.

Wunderlich FT, Wilder H, Rajewsky K \& Edenhofer F 2001 New variants of inducible Cre recombinase: a novel mutant of Cre-PR fusion protein exhibits enhanced sensitivity and an expanded range of inducibility. Nucleic Acids Research 29 e47.

Xu X, Wagner K-U, Larson D, Weaver Z, Li C, Ried T, Hennighausen L, Wynshaw-Boris A \& Deng C-X 1999 Conditional mutation of Brca1 in mammary epithelial cells results in blunted ductal morphogenesis and tumour formation. Nature Genetics 22 37-43.

Yakar S, Liu J-L, Stannard B, Butler A, Accili D, Sauer B \& LeRoith D 1999 Normal growth and development in the absence of hepatic insulin-like growth factor I. PNAS 96 7324-7329.

Yakar S, Liu JL, Fernandez AM, Wu Y, Schally AV, Frystyk J, Chernausek SD, Mejia W \& Le Roith D 2001 Liver-specific igf-1 gene deletion leads to muscle insulin insensitivity. Diabetes $\mathbf{5 0}$ 1110-1118.

Yamamoto A, Lucas JJ \& Hen R 2000 Reversal of neuropathology and motor dysfunction in a conditional model of Huntington's disease. Cell 101 57-66.

Yu RN, Ito M, Saunders TL, Camper SA \& Jameson JL 1998 Role of Ahch in gonadal development and gametogenesis. Nature Genetics 20 353-357.

Zaher H, Yang TJ, Gelboin HV, Fernandez-Salguero P \& Gonzalez FJ 1998 Effect of phenobarbital on hepatic CYP1A1 and CYP1A2 in the Ahr- null mouse. Biochemical Pharmacology 55 235-238.

Zhao L, Bakke M, Krimkevich Y, Cushman LJ, Parlow AF, Camper SA \& Parker KL 2001 Steroidogenic factor 1 (SF1) is essential for pituitary gonadotrope function. Development 128 147-154.

Zheng B, Sage M, Sheppeard EA, Jurecic V \& Bradley A 2000 Engineering mouse chromosomes with Cre-loxP: range, efficiency, and somatic applications. Molecular and Cellular Biology 20 648-655.

Zhu Z, Ma B, Homer RJ, Zheng T \& Elias JA 2001 Use of the tetracycline controlled transcriptional silencer (tTS) to eliminate transgene leak in inducible overexpression transgenic mice. Journal of Biological Chemistry 276 25222-25229.

Received 4 June 2001

Accepted 5 July 2001 